\title{
Mortality and cardiovascular disease burden of uncontrolled diabetes in a registry-based cohort: the ESCARVAL-risk study
}

\author{
Jorge Navarro-Pérez ${ }^{1,2 \dagger}$, Domingo Orozco-Beltran ${ }^{3 \dagger}$, Vicente Gil-Guillen ${ }^{3}$, Vicente Pallares ${ }^{4}$, Francisco Valls ${ }^{5}$, \\ Antonio Fernandez ${ }^{6}$, Ana María Perez-Navarro ${ }^{6}$, Carlos Sanchis ${ }^{7}$, Alejandro Dominguez-Lucas ${ }^{1}$, \\ Jose M. Martin-Moreno ${ }^{8}$, Josep Redon ${ }^{1,9,11^{*}}$ (D), Maria Tellez-Plaza ${ }^{1,10}$ and on behalf of the ESCARVAL STUDY GROUP
}

\begin{abstract}
Background: Despite the epidemiological evidence about the relationship between diabetes, mortality and cardiovascular disease, information about the population impact of uncontrolled diabetes is scarce. We aimed to estimate the attributable risk associated with $\mathrm{HbA1c}$ levels for all-cause mortality and cardiovascular hospitalization.

Methods: Prospective study of subjects with diabetes mellitus using electronic health records from the universal public health system in the Valencian Community, Spain 2008-2012. We included 19,140 men and women aged 30 years or older with diabetes who underwent routine health examinations in primary care.

Results: A total of 11,003 (57\%) patients had uncontrolled diabetes defined as HbA1c $\geq 6.5 \%$, and, among those, 5325 participants had HbA1c $\geq 7.5 \%$. During an average follow-up time of 3.3 years, 499 deaths, 912 hospitalizations for coronary heart disease (CHD) and 786 hospitalizations for stroke were recorded. We observed a linear and increasingly positive dose-response of $\mathrm{HbA1c}$ levels and $\mathrm{CHD}$ hospitalization. The relative risk for all-cause mortality and $\mathrm{CHD}$ and stroke hospitalization comparing patients with and without uncontrolled diabetes was $1.29(95 \mathrm{Cl} 1.08,1.55), 1.38(95 \mathrm{Cl} 1.20,1.59)$ and 1.05 (95 Cl 0.91, 1.21), respectively. The population attributable risk (PAR) associated with uncontrolled diabetes was 13.6\% (95\% Cl; 4.0-23.9) for all-cause mortality, 17.9\% (95\% Cl; 10.5-25.2) for CHD and 2.7\% (95\% Cl; - 5.5-10.8) for stroke hospitalization.
\end{abstract}

Conclusions: In a large general-practice cohort of patients with diabetes, uncontrolled glucose levels were associated with a substantial mortality and cardiovascular disease burden.

Keywords: HbA1c, Diabetes, Attributable risk, All-cause mortality, Hospitalization, Coronary heart disease, Stroke

\section{Introduction}

Prolonged exposure to hyperglycemia results in vascular damage [1]. The association between chronic hyperglycemia and cardiovascular complications, however, is not fully understood [2]. The HbA1c level is an indicator of the average blood glucose concentrations over the

\footnotetext{
* Correspondence: josep.redon@uv.es

${ }^{\dagger}$ Jorge Navarro-Pérez and Domingo Orozco-Beltran contributed equally to this work.

${ }^{1}$ Biomedical Research Institute INCLIVA, Hospital Clinico Universitario de Valencia, University of Valencia, Valencia, Spain

${ }^{9}$ CIBERObn, Instituto de Salud Carlos III, Madrid, Spain

Full list of author information is available at the end of the article
}

preceding 2-3 months and is used as a biomarker of diabetes control in clinical practice [3]. There is much evidence on the role of hyperglycemia as a cardiovascular disease (CVD) risk factor, sudden death [4], mortality in myocardial infarction [5] and mortality in critically ill patients [6], despite the fact that elevated HbA1c has shown inconsistent risk stratification, according to different levels [7, 8]. Observational studies and metaanalyses report that patients with uncontrolled diabetes, defined as $\mathrm{HbA} 1 \mathrm{c}>6.5 \%$, are at increased risk for CVD and mortality compared to patients with controlled diabetes $[7,8]$. Moreover, post hoc analyses from the

(c) The Author(s). 2018 Open Access This article is distributed under the terms of the Creative Commons Attribution 4.0 International License (http://creativecommons.org/licenses/by/4.0/), which permits unrestricted use, distribution, and 
Action to Control Cardiovascular Risk in Diabetes (ACCORD) [9]; the Action in Diabetes and Vascular Disease: Preterax and Diamicron Modified Release Controlled Evaluation (ADVANCE) [10], and the Veterans Affairs Diabetes Trial (VADT) [11], suggested different effects of glycemic control in patients with and without previous vascular disease. Furthermore, the HbA1c level is an independent risk factor for $\mathrm{CV}$ events, regardless of the diabetes diagnosis [12-15].

Despite the large number of studies analysing the prognostic value of HbA1c levels, information about the population impact associated with uncontrolled diabetes is scarce. The fraction of mortality and CVD potentially avoidable by achieving certain HbA1c levels in the population of individuals with diabetes has not been evaluated, and can be estimated by using real world data from Electronic Health Recording (EHR) [16]. Moreover, EHR-based studies from general-practice settings may provide a privileged view of the burden of disease associated to uncontrolled diabetes in the whole population. The ESCARVAL-RISK study, based on HER, is a cohort of beneficiaries of the universal health care system of the Valencian Community, (Spain), with CV risk factors, including diabetes, considered by a network of general practice physicians [17-19]. The objective of the present study was to estimate the attributable risk of all-cause mortality and $\mathrm{CV}$ hospitalization associated to elevated HbA1c levels in a cohort of patients with diabetes mellitus from the ESCARVAL-RISK study.

\section{Materials and methods}

\section{Study population and baseline data collection}

The sample was recruited from beneficiaries of the Valencian Health Agency's universal health care system. The Valencian Community is a Mediterranean region located on the East-coast of Spain, with a population of $3,205,724$ people older than 30 years in 2007. Total population data was extracted using the health information exchange function of ABUCASIS for the period of time between 1st January 2008 and 31st December 2012. ABUCASIS includes information on patient demographics, medications, vital status, past medical history and laboratory data, among others. Detailed information about the ESCARVALRISK project and data collection methods has been previously published [17-19].

Eligible patients for the present study were men and women with diabetes mellitus and free of CV disease. Participants were included in the study from 1st January 2008 if they fulfilled the eligibility conditions of a diagnosis of diabetes as a non-fasting glucose level of $\geq 200 \mathrm{mg} / \mathrm{dl}$, a recorded physician diagnosis, use of glucose lowering drugs or insulin, or $\mathrm{HbA} 1 \mathrm{c} \geq 6.5 \%$.
Subsequently, participants newly diagnosed with these conditions during the study period were also included. The ESCARVAL-RISK is an observational study with the described previously characteristics [17-19]. Patient data was saved from various occasions and locations when they had received care, such as in the primary care physician's office, as well as other physician specialists, nurses' offices, pharmacies, hospitals, and emergency departments. As a result, not all the baseline variables that were needed to adjust for potential confounding in this study were available at the exact time of inclusion. We thus defined 6-month windows around the time of study inclusion in order to gather complete information on biochemistry results and blood pressure determinations) and excluded patient with missing dat. Finally, 19,140 diabetic subjects of both sexes aged 30 years or older who attended routine health examinations and fulfilled eligibility criteria were selected from the total population database. The STROBE chart is in Fig. 1.

\section{Cardiovascular risk factors definition}

Body mass index (BMI) was calculated by dividing measured weight in kilograms by measured height in metres squared. Obesity was defined as a BMI $\geq 30 \mathrm{~kg} / \mathrm{m}^{2}$. Blood pressure was measured up to three times on the same day in a sitting position and hypertension was defined as an office mean systolic blood pressure $\geq 140 \mathrm{mmHg}$, a mean diastolic blood pressure $\geq 90 \mathrm{mmHg}$, a recorded physician diagnosis, or antihypertensive medication use. Serum total cholesterol was measured enzymatically using the Cholesterol High Performance reagent (Roche Diagnostics). High density-lipoprotein (HDL) cholesterol was measured using a direct HDL reagent (Roche

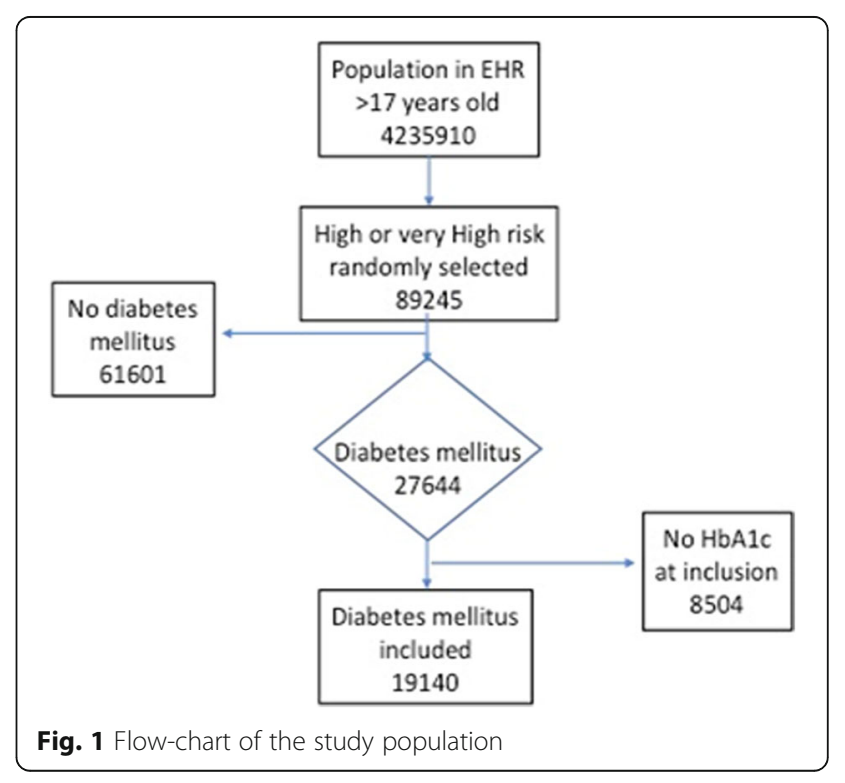


Diagnostics). Low density-lipoprotein LDL cholesterol was calculated by using the Friedwald formula, considering the triglyceride levels. High cholesterol was defined as a serum total cholesterol $>200 \mathrm{mg} / \mathrm{dL}$, recorded diagnosis or medication use. HbA1c was assessed by the labs of different hospitals of the Valencia Community using High performance Liquid Chromatography (HPLC).

\section{Mortality and hospitalization follow-up}

ESCARVAL-RISK participants were followed for allcause mortality or the first episode of hospitalization for myocardial infarction or stroke until 31st December 2012. Causes of hospitalization were recorded using codes of the International Classification of Diseases, 9th Revision. Vital status was determined by matching ESCARVAL records and death certificates from the Spanish National Death Index. Mortality included all causes of death. Cause-specific hospitalization was defined as the first hospital admission for CHD (ICD-9 codes 410-414), and stroke (ICD-9 codes 430-438, 444). Time to event was calculated for each individual as the difference between the date of the inclusion into the study and the date of the hospital admission, the date of death, or 31st December 2012, whichever occurred first. A minimum follow-up period of one year was required.

\section{Confidentiality and ethics requirements}

Patients' data collected from the ABUCASIS system during the study were documented and pseudo-anonymized. The data generated during the study was handled according to Spanish Law 5/1999 and corresponding to
European norms. The study was conducted according to the standards of the International Guidelines for Ethical Review of Epidemiological Studies (Council for International Organizations of Medical Sciences-CIOMS-Geneva, 1991) and the recommendations of the Spanish Society of Epidemiology about the review of ethical aspects of epidemiological research. The ESCARVAL-RISK study was reviewed and approved by the Committee for Ethics and Clinical Trials of the Center for Public Health Research (DGSP-CSISP).

\section{Statistical analysis}

HbA1c levels were normally distributed and cut-offs for HbA1c categories and other quantiles used in the analysis were based on the distribution in the study sample. In descriptive analyses, we used generalised linear models to estimate means and proportions of participants' characteristics, overall and by $\mathrm{HbAlc}$ categories. We also estimated, age and sex-adjusted rates for mortality and CV hospitalization end-points using Poisson regression for individual data with over-dispersion correction. Multi-adjusted rate differences were estimated from semi-parametric Aalen additive hazard models. To graphically display non-linear relationships, we used restricted quadratic splines with knots at the 20th, 50th and 80th percentiles of HbA1c distribution. Statistical models were adjusted for potential confounders.

Population attributable risks (PARs) for high HbAlc were calculated by using the standard formula PAR $=1-\Sigma_{j} \Sigma_{i} p_{i j}$ $\mid R R_{i \mid j}[17,18]$. In this formula, the subscript $i$ denotes one of two categories of HbA1c levels (with each participant classified as above or below the cut-off being used to calculate the PAR, respectively), the subscript $j$ is an index for all

Table 1 Baseline Characteristics of Study Participants Overall and by Glycated Hemoglobine categories

\begin{tabular}{|c|c|c|c|c|c|c|c|}
\hline & $\begin{array}{l}\text { Overall } \\
(N=19,140)\end{array}$ & $\begin{array}{l}<6 \\
(N=4304)\end{array}$ & $\begin{array}{l}6-6.5 \\
(N=3773)\end{array}$ & $\begin{array}{l}6.5-7 \\
(N=3339)\end{array}$ & $\begin{array}{l}7-7.5 \\
(N=2399)\end{array}$ & $\begin{array}{l}>=7.5 \\
(N=5325)\end{array}$ & p-trend \\
\hline Age, years; mean & $65.1(0.1)$ & $65.4(0.2)$ & $66.2(0.2)$ & $66(0.2)$ & $66.2(0.2)$ & $62.9(0.2)$ & $<0.001$ \\
\hline Men; \% & $54.3(0.4)$ & $54.8(0.8)$ & $50(0.8)$ & $51.4(0.9)$ & $53.3(1)$ & $59(0.7)$ & $<0.001$ \\
\hline Obesity; \% & $49.6(0.4)$ & $47.4(0.8)$ & $51.5(0.8)$ & $49.3(0.9)$ & $49.7(1)$ & $50.1(0.7)$ & 0.098 \\
\hline $\mathrm{BMI}, \mathrm{kg} / \mathrm{m}^{2}$; mean & $30.4(0)$ & $30.2(0.1)$ & $30.6(0.1)$ & $30.4(0.1)$ & $30.5(0.1)$ & $30.5(0.1)$ & 0.05 \\
\hline Former smoking; $\%$ & $23.4(0.3)$ & $24(0.7)$ & $23.2(0.7)$ & $22.6(0.7)$ & $22.9(0.9)$ & $23.8(0.6)$ & 0.875 \\
\hline Current smoking; \% & $21.6(0.3)$ & $18.5(0.6)$ & $18.4(0.6)$ & $20.1(0.7)$ & $20.5(0.8)$ & $27.8(0.6)$ & $<0.001$ \\
\hline Glucose lowering medication; \% & $51.8(0.4)$ & $38.8(0.7)$ & $45.6(0.8)$ & $52(0.9)$ & $60(1)$ & $62.8(0.7)$ & $<0.001$ \\
\hline Hypertension; \% & $83.2(0.3)$ & $83.8(0.6)$ & $84.1(0.6)$ & $84.4(0.6)$ & $83.6(0.8)$ & $81(0.5)$ & $<0.001$ \\
\hline Antihypertensive medication; \% & $49(0.4)$ & $50.4(0.8)$ & $50.2(0.8)$ & $52.4(0.9)$ & $50.3(1)$ & $44.3(0.7)$ & $<0.001$ \\
\hline Systolic blood pressure, mmHg; mean & $138(0.1)$ & $136.1(0.3)$ & $137(0.3)$ & $138.3(0.3)$ & $138.8(0.4)$ & $139.9(0.3)$ & $<0.001$ \\
\hline Diastolic blood pressure, $\mathrm{mmHg}$; mean & $78.6(0.1)$ & $78(0.2)$ & $78.3(0.2)$ & $78.7(0.2)$ & $78.3(0.2)$ & $79.4(0.1)$ & $<0.001$ \\
\hline High cholesterol; \% & $16.7(0.3)$ & $18.1(0.6)$ & $17.2(0.6)$ & $16.8(0.7)$ & $16.8(0.8)$ & $15(0.5)$ & $<0.001$ \\
\hline Total cholesterol, mg/dL; mean & $197.5(0.3)$ & $195.5(0.6)$ & $197(0.7)$ & $196.3(0.7)$ & $194.3(0.8)$ & $201.8(0.6)$ & $<0.001$ \\
\hline HDL-cholesterol, mg/dL; mean & $48.9(0.1)$ & $50.3(0.2)$ & $49.9(0.2)$ & $49.4(0.2)$ & $48.6(0.3)$ & $46.8(0.2)$ & $<0.001$ \\
\hline LDL-cholesterol, mg/dL; mean & $116.6(0.2)$ & $116.1(0.5)$ & $116.3(0.5)$ & $115.3(0.6)$ & $113.7(0.7)$ & $119.3(0.5)$ & $<0.001$ \\
\hline Lipid lowering medication; \% & $38(0.3)$ & $35.6(0.7)$ & $39.2(0.8)$ & $40.1(0.9)$ & $40.7(1)$ & $36.6(0.7)$ & 0.458 \\
\hline
\end{tabular}


Table 2 Age and Sex-adjusted rates (events/10,000 person-years) of all-cause mortality and CVD hospitalization by quartile of HbA1c

\begin{tabular}{|c|c|c|c|c|c|c|}
\hline & \multicolumn{5}{|c|}{ Glycated Hemoglobin categories } & \multirow[t]{2}{*}{$p$-value } \\
\hline & $\begin{array}{l}<6 \\
(N=4304)\end{array}$ & $\begin{array}{l}6-6.5 \\
(N=3773)\end{array}$ & $\begin{array}{l}6.5-7 \\
(\mathrm{~N}=3339)\end{array}$ & $\begin{array}{l}7-7.5 \\
(\mathrm{~N}=2399)\end{array}$ & $\begin{array}{l}>=7.5 \\
(N=5325)\end{array}$ & \\
\hline \multicolumn{7}{|l|}{ Glycated Hemoglobin } \\
\hline Median (range), mg/dL & $5.6(4.6,5.9)$ & $5.6(6,6.4)$ & $6.7(6.5,6.9)$ & $7.2(7,7.4)$ & $8.4(7.5,12.6)$ & \\
\hline \multicolumn{7}{|l|}{ All-cause mortality } \\
\hline Cases (person-year) & $116(15,346.42)$ & $80(12,801.36)$ & $72(11,233.22)$ & $60(8174.11)$ & $171(17,893.89)$ & \\
\hline Rate & 72.1 & 59.6 & 60.7 & 68.8 & 104.8 & $<0.001$ \\
\hline \multicolumn{7}{|l|}{ CHD hospitalization } \\
\hline Cases (person-year) & $169(14,979.12)$ & $154(12,477.02)$ & $155(10,951.90)$ & $123(7936.55)$ & $311(17,329.30)$ & \\
\hline Rate & 110.8 & 122.6 & 139.0 & 150.8 & 185.3 & $<0.001$ \\
\hline \multicolumn{7}{|l|}{ Stroke hospitalization } \\
\hline Cases (person-year) & $161(15,025.62)$ & $166(12,480.03)$ & $126(11,002.67)$ & $90(8016.53)$ & $243(17,442.46)$ & \\
\hline Rate & 104.9 & 128.6 & 109.1 & 106.3 & 150.6 & 0.004 \\
\hline
\end{tabular}

strata obtained after cross-classifying the study sample for all adjusted covariates, $p_{i j}$ is the proportion of cases over all cases in the study population in each stratum after cross-classifying the dichotomous HbA1c categories and all adjusted covariates, and $R R_{i \mid j}$ is the adjusted hazard ratio for the endpoint of interest comparing participants below and above the HbA1c cut-off in stratum $j$ of covariates, from Cox proportional hazards regression. We calculated adjusted PARs for HbA1c > 6.5\% from separate models fully adjusted for age (restricted quadratic splines with 5 knots), sex, smoking status (never, former, current), obesity (no, yes), hypertension (no, yes), chronic kidney disease (no, yes), anti-hypertensive medication (no, yes), glucose lowering medication (no, yes), lipid lowering medication (no, yes).

\section{Results}

\section{Participant characteristics}

The mean age was 65.1 years and $54.3 \%$ were males. At baseline, 49.6\% participants were obese (average BMI $30.4 \mathrm{~kg} / \mathrm{m} 2$ ), $83.2 \%$ participants had hypertension and $16.7 \%$ participants showed total cholesterol $>200 \mathrm{mg} / \mathrm{dl}$, (among those, 38\% were receiving lipid lowering drugs). $11,003(57 \%)$ patients had uncontrolled diabetes defined as HbA1c $\geq 6.5 \%$, and, among those, 5325 participants had $\mathrm{HbA} 1 \mathrm{c} \geq 7.5 \%$. Patients were treated with insulin, $8.3 \%$, and $43.5 \%$ with different oral glucose lowering agents. The main characteristics of the study population by HbA1c levels are shown in Table 1. Participants with increasing HbA1c levels showed increasing current smoking and glucose lowering medication status and decreasing HDL cholesterol levels.

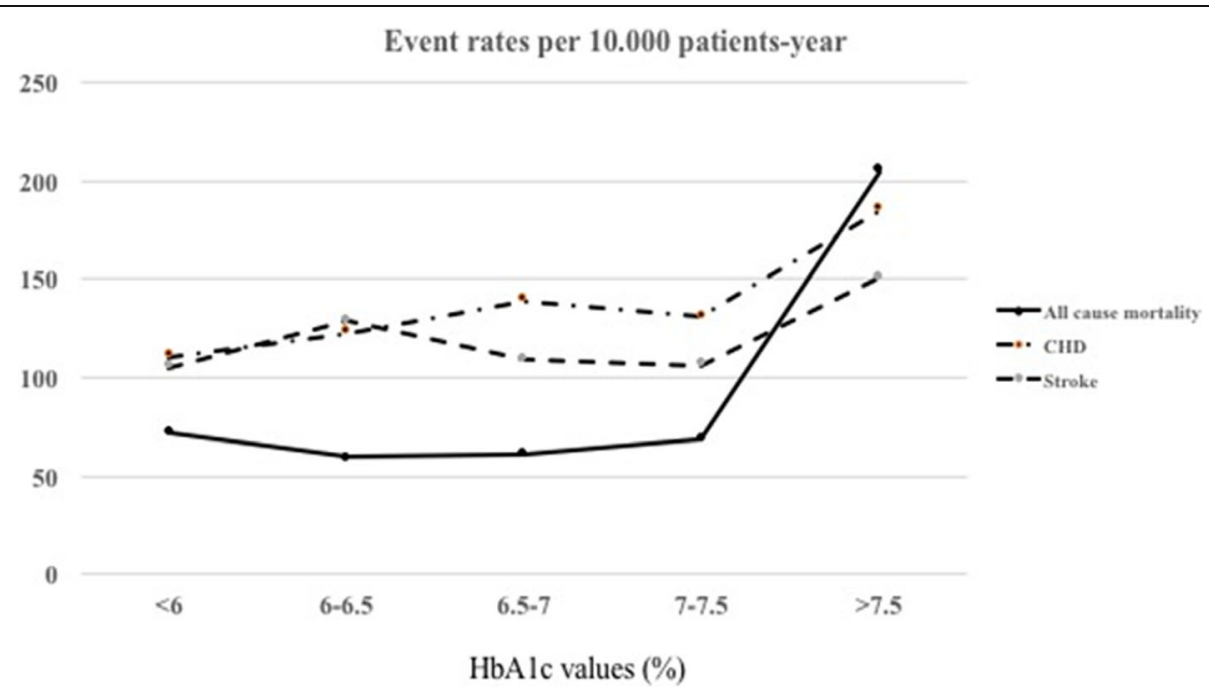

Fig. 2 Age and Sex-adjusted rates (events/10,000 person-years) of all-cause mortality and CVD hospitalization by quartile of HbA1C 


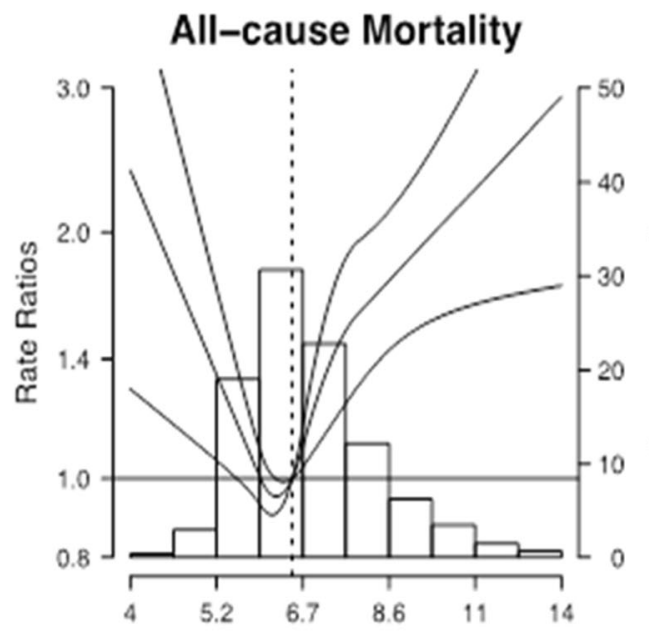

Glycated Hemoglobin (\%)

\section{CHD hospitalization}

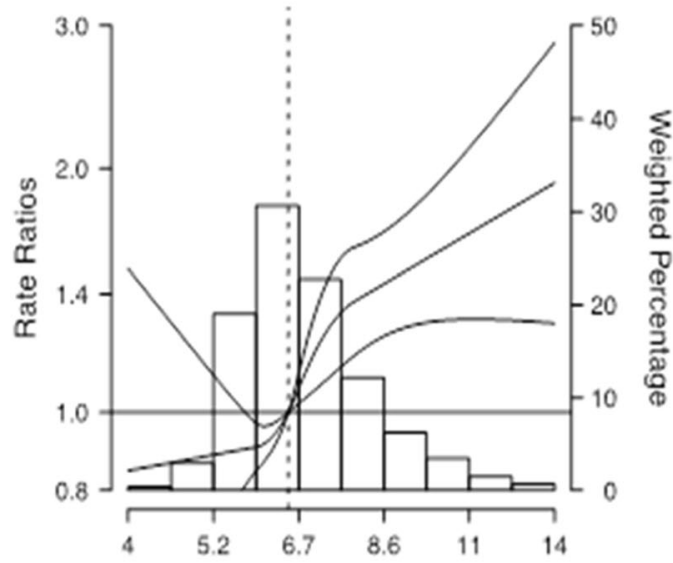

Glycated Hemoglobin (\%)

\section{Stroke hospitalization}

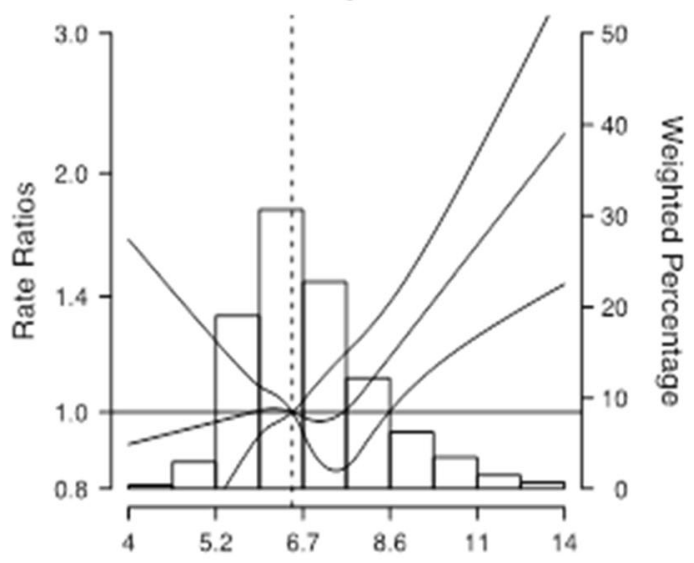

Glycated Hemoglobin (\%)
Fig. 3 Adjusted Odds Ratios ( $95 \%$ Cl) of Mortality and morbidity by Glycated Hemoglobin levelsThe curve represents adjusted rate ratio (RR) of mortality (panel 1), CHD hospitalization (panel 2) and stroke hospitalization (panel 3) by glycated hemoglobin levels, based on restricted quadratic splines with knots at the 10th, 50th, and 90th percentiles $(5.6 \%, 6.7 \%$ and $8.9 \%$, respectively) of the glycated hemoglobin distribution. The reference value $(R R=1)$ was set at $5.6 \%$ of the Glycated Hemoglobin. RRs were adjusted for age (restricted quadratic splines with 5 knots), sex, smoking status (never, former, current), obesity (no, yes), hypertension (no, yes), chronic kidney disease (no, yes), HDL cholesterol $\leq 40$ for men and $\leq 50$ for women (no, yes), LDL $\geq 130 \mathrm{mg} / \mathrm{dL}$ (no, yes), anti-hypertensive medication (no, yes), glucose lowering medication (no, yes), lipid lowering medication (no, yes). For a given value (\%) of glycated hemoglobin distribution, the corresponding RR is interpreted as the expected change in the rate of mortality and CVD hospitalization, associated to changing glycated hemoglobin from a given value, to the reference (6.5\%). For example, model estimates suggest that the RR for mortality of participants in the 90th percentile of glycated hemoglobin (8.9\%) is $80 \%$ higher, compared to participants in the Reference (6.5\%).

\section{Dose-response associations}

During an average follow-up of 3.3 years, the EHR recorded 499 deaths, 912 hospitalizations for CHD and 786 hospitalizations for stroke. The age and sex-adjusted rates and events/10,000 person-years for all-cause mortality and CVD hospitalization by HbA1c levels are shown in Table 2 and Fig. 2. We observed a fairly linear and increasingly positive dose-response of CHD hospitalization by HbA1c levels (Table 2, Fig. 3, panel 2). For all-cause mortality, however, the dose-response by HbA1c levels was non-linear (Fig. 3, panel 1). For stroke hospitalization, the dose response was statistically significant only in the higher range of HbA1c distribution (Fig. 3, panel 3).

\section{Burden of disease associated to $\mathrm{HbA1c}$ level}

In additive hazard models, the absolute risk differences for CHD hospitalization also progressively increased from 11.41 events/10,000 person-years for HbA1c levels between 6 and $6.5 \%$, to 70.26 events/10,000 person-years for HbA1c levels greater than 7\% (Table 3). The relative risk for all-cause mortality and CHD and stroke hospitalization comparing patients with and without uncontrolled diabetes was 1.29 (95 CI 1.08,1.55), 1.38 (95 CI $1.20,1.59$ ) and 1.05 (95 CI $0.91,1.21$ ), respectively. The corresponding population attributable risk (PAR) associated with uncontrolled diabetes was 13.6\% (95\% CI; 4.0-23.9) for all-cause mortality, $17.9 \%$ (95\% CI; 10.5-25.2) for CHD and 2.7\% (95\% CI; - 5.5-10.8) for stroke hospitalization (Table 4).

\section{Discussion}

In a large cohort of individuals with diabetes from a Mediterranean region in Spain, glucose control assessed 


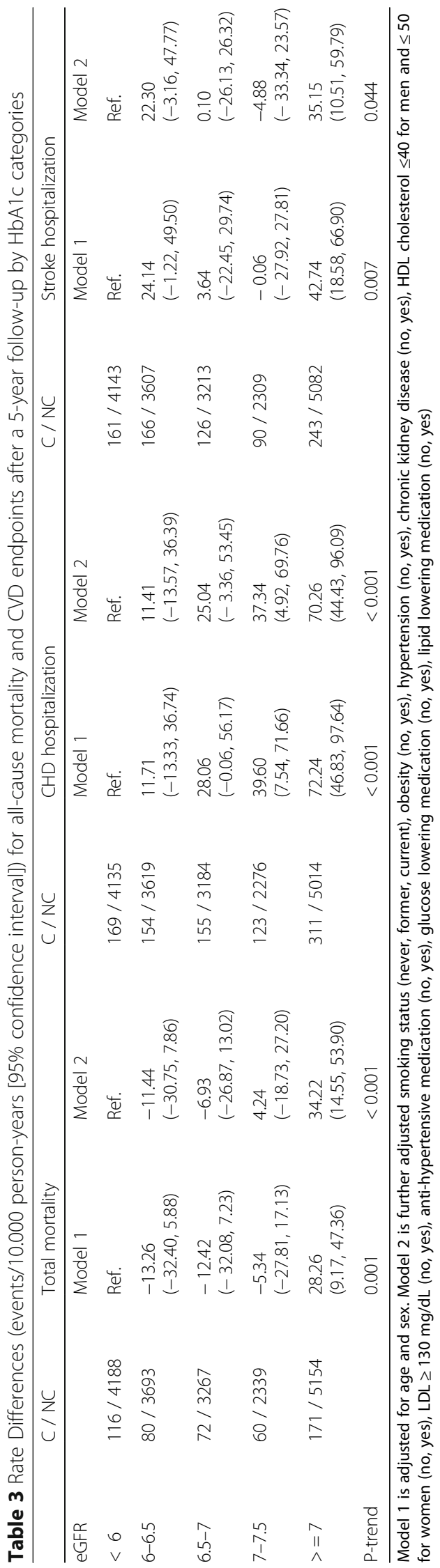


Table 4 Population attributable risk of all-cause mortality and CVD hospitalization, associated to HbA1c $>6.5 \%$

\begin{tabular}{llll}
\hline & $\begin{array}{l}\text { All-cause } \\
\text { mortality }\end{array}$ & $\begin{array}{l}\text { CHD } \\
\text { hospitalization }\end{array}$ & $\begin{array}{l}\text { Stroke } \\
\text { hospitalization }\end{array}$ \\
\hline $\begin{array}{l}\text { Cases/ } \\
\text { Non-cases }\end{array}$ & $499 / 18,598$ & $912 / 18,185$ & $786 / 18,311$ \\
RR & $1.29(1.08,1.55)$ & $1.38(1.2,1.59)$ & $1.05(0.91,1.21)$ \\
PAR \% & $13.62(3.96,22.90)$ & $17.90(10.53,25.20)$ & $2.64(-5.51,10.76)$ \\
\hline
\end{tabular}

Model is fully adjusted for age (restricted quadratic splines with 5 knots), sex, smoking status (never, former, current), obesity (no, yes), hypertension (no, yes), chronic kidney disease (no, yes), anti-hypertensive medication (no, yes), glucose lowering medication (no, yes), lipid lowering medication (no, yes). The prevalence of glycated hemoglobin $>6.5 \%$ was $57.78 \%$

by $\mathrm{HbA1c}$ levels was positively related to the risk of all-cause mortality, as well as hospitalization by $\mathrm{CHD}$, starting with HbA1c levels greater than $\sim 6 \%$. The association with stroke hospitalization, however, was only significant in the higher range of HbA1c levels. The fraction of potentially avoidable deaths associated with having HbA1c below $6.5 \%$ was $14 \%$. The corresponding fraction of avoidable CHD hospitalizations was 18\% (Table 5).

The present study was conducted in a population with a country-specific low $\mathrm{CV}$ risk profile as referenced by the SCORE study [20], even though the prevalence of diabetes is $13.8 \%$ [21]. In the whole Valencian Community territory, the EHR associated with the public general-practice setting has a $92 \%$ coverage of the population living in the area [22]. Every patient has a unique personal identification number which guarantees the interoperability of the EHRs. Thus, administrative data, including all prescriptions and dispensation of subsidized treatments for diabetes and hospitalization events are linked to the database that integrates all the health care interventions and procedures that the patients received. Therefore, this study includes information on baseline risk factors and followup for mortality and CV hospitalizations from essentially all adults with diabetes mellitus in the region who had their HAbla levels measured by the public health system during the study period.

Table 5 Main messages on the mortality and cardiovascular disease burden of uncontrolled diabetes in a registry-based cohort: the ESCARVAL-risk study

\footnotetext{
Main messages

There is much evidence on the role of hyperglycemia as a

cardiovascular disease

The HbA1c level is used as a biomarker of diabetes control in clinical practice and is an independent risk factor for CV events, regardless of the diabetes diagnosis

Information about the population impact associated with uncontrolled diabetes is scarce

In a large cohort of individuals with diabetes, HbA1c levels was positively related to the risk of all-cause mortality, as well as hospitalization by $\mathrm{CHD}$, starting with $\mathrm{HbA} 1 \mathrm{c}$ levels $>6 \%$.

The fraction of potentially avoidable deaths associated with having $\mathrm{HbA} 1 \mathrm{c}$ below $6.5 \%$ was $14 \%$ and the corresponding fraction of avoidable CHD hospitalizations was 18\%.
}

The present study supports that the risk of death and CHD hospitalization is related to glucose-control and points to the substantial potential for prevention associated to lowering HbA1c levels. Despite the epidemiological evidence about the relationship between glucose control, assessed by $\mathrm{HbA1c}$, and CV events, randomized clinical trials did not show a benefit of better glucose-control in reducing risk. Thus, evidence was not sufficient to generate strong recommendations for clinical practice. In fact, the evidence was graded $\mathrm{IIa} / \mathrm{C}$ in the ACCF/AHA guidelines for assessment of $\mathrm{CV}$ risk in asymptomatic adults [23] and by the ESC-EARD [24]. Recent revisions of guidelines from Scientific Societies moved away from uniform recommendations and towards a more nuanced patient-centered approach to HbA1c therapeutic targets [25]. It is possible that a minimum study duration and a minimum gain in $\mathrm{HbA} 1 \mathrm{c}$ reduction are necessary to drive a relevant risk reduction in $\mathrm{CV}$ risk [26]. In the absence of conclusive evidence from RCTs, observational epidemiological studies using real world data [27] might provide additional useful information to clarify the attributable risk of glucose control in CV risk.

The population impact of uncontrolled diabetes in the present study is displayed in three ways. First, we show age and sex-adjusted absolute rates for mortality or hospitalization for CHD or stroke by HbA1c subgroups of interest. The rate of CHD hospitalization shows a progressive increment from the lowest to the highest level, while the rate of stroke hospitalization is less constant across the HbA1c categories. In agreement with the present study, a meta-analysis showed that $1 \%$ HbA1c reduction was associated with a lowered major $\mathrm{CV}$ risk by glycemic control, but was not associated with lowered stroke and death risks [7]. Studies with strong association with stroke come from Taiwan [28] and Korea [8], in which the risk of stroke is high compared with Caucasians. For all-cause mortality, but not for CHD or stroke hospitalization, a U-shape curve was observed, such as that in the UK GPRD and ARIC, studies that showed increased risk of all-cause death with both lower and higher HbA1c levels $[13,29]$. However, the U-shaped curve was not confirmed in other studies such as the Swedish National Diabetes Register cohort [30].

Second, we calculated the multi-adjusted rate differences in mortality or hospitalizations (also termed "attributable risk"), comparing patients with progressively increasing HbA1c levels to HbA1c levels lower than 6\%. This can be interpreted as the average annual increase in mortality and $\mathrm{CV}$ disease hospitalization risk on an absolute scale attributable to HbA1c categories adjusting for potential confounders. In both all-cause mortality and stroke hospitalization the attributable risks were only statistically 
significant at $\mathrm{HbA1c}>7.5 \%$. For $\mathrm{CHD}$ hospitalization, however, the attributable risk became borderline statistically significant at the $6.5 \%$ cut-off, but displayed a progressive increase across $\mathrm{HbAlc}$ categories. Moreover, at the higher range of HbAlc levels, the attributable risk for $\mathrm{CHD}$ hospitalization doubles. These results have not been previously reported in other cohorts of patients with diabetes, but support the current target levels of HbA1c $<7 \%$ recommended by the guidelines of the American Diabetes Association [31].

Third, we estimated the adjusted PAR associated to uncontrolled diabetes defined as HbA1c $>6.5 \%$, which represents the estimated fraction of deaths that would be avoided in the population. This assumes that the effects are causal and that other risk factors remained unchanged, and therefore suggests that strict diabetes control could relevantly diminish the $\mathrm{CV}$ disease burden of diabetes. More studies are needed to confirm the findings.

The study needs to be considered within its strengths and limitations. The main limitation of the present study is the lack of information about the duration and progression of the $\mathrm{CV}$ risk factors. Thus, some degree of residual confounding cannot be discarded. Another limitation is the absence of HbA1c follow-up data; therefore, it was not possible to test the potential role of HbA1c individual trajectories on mortality and $\mathrm{CV}$ risk. In addition, the ascertainment of CHD and stroke hospitalizations was performed mainly through hospital discharge codes, which may have led to the under-ascertainment of cases that perhaps were not severe enough to warrant hospitalization. Finally, it is possible that findings from this Mediterranean cohort are not generalizable to other populations. However, the EHR system of the Valencian Community (ABUCASIS), which is the framework for the ESCARVAL project, allowed the monitoring of a population-based sample of individuals with diabetes throughout their experience in a general practice system. While the follow-up time in this study was not long, the large sample size, however, provided enough power and a valuable frame to assess the attributable risk of mortality and CHD and stroke associated to diabetes control in the short term. This provides a common scale for comparing the potential population-level impact of interventions for disease prevention.

\section{Conclusions}

In conclusion, in a large general-practice cohort of patients with diabetes, uncontrolled diabetes was associated with a substantial mortality and CV disease burden. While our results support a potential benefit of decreasing HbA1c levels below the traditional 6.5\% threshold in patients with diabetes, additional studies are needed to confirm these findings.

\section{Abbreviations}

ACCF/AHA: American College of Cardiology/American Heart Association; ARIC: Atherosclerosis Risk in Communities; BMI: Body Mass Index; CHD: Hospitalizations for Coronary Heart Disease; Cl: Confidence Interval; CV: Cardiovascular; CVD: Cardiovascular Disease; EHR: Electronic Health Recording; ESC-EARD: European Society of Cardiology - European Association for the Study of Diabetes; HbA1c: Glycated Haemoglobin; HDL: High Density Lipoprotein; HPLC: High Performance Liquid Chromatography; LDL: Low Density Lipoprotein; PAR: Population Attributable Risk; RCTs: Randomized Clinical Trials; UK GPRD: United Kingdom General Practice Research Database

\section{Consent form}

The consent form was waived due to there being no patient-intervention, no possibility to obtain it and considering that the database in our hands has been pseudo-anonymized by the Health Care Authorities before its release, with no possibility to revert the information.

\section{Funding}

This work was supported by: EU-MASCARA HEALTH, 2011.2.4.2-2 European Commission, 7th Framework Programme; and the grants PS09/02014, SAF2011-23029 and PI 12/02615 and the Strategic Action for Research in Health sciences [CP12/03080, PI10/0082, PI13/01848 and PI11/00726] of the Health Institute Carlos III, CIBER Fisiopatología Obesidad y Nutrición (CIBERObn) [CIBER-02-08-2009, CB06/03 and CB12/03/30016]. The Strategic Action for Research in Health sciences and CIBERObn are initiatives from Carlos III Health Institute Madrid and the Spanish Ministry of Economy and Competitiveness and co-funded with European Funds for Regional Development (FEDER).

\section{Availability of data and materials \\ Data are property of the Health Authorities of the Valencia Community, Spain.}

\section{Consent for publication}

Not applicable.

\section{Authors' contributions}

JNP, DOB, VGG, VP, FV, AF, AMPN, CS, ADL, JMMM, JR, MTP. Design of the study: JNP, DOB, VGG, JR. Database handling: AF, AMPN, ADL, JMMM, VP, FV, CS. Statistical analysis: MTP, JR. Writing the manuscript: JR, MTP. All authors read and approved the manuscript.

\section{Ethics approval}

The study was aproved by the "(CEIC de la Dirección General de Salud Pública y Centro Superior de Investigación en Salud Pública at March 14th, 200814 de marzo del año 2.008)".

\section{Competing interests}

The authors declare that they have no competing interests.

\section{Publisher's Note}

Springer Nature remains neutral with regard to jurisdictional claims in published maps and institutional affiliations.

\footnotetext{
Author details

${ }^{1}$ Biomedical Research Institute INCLIVA, Hospital Clinico Universitario de Valencia, University of Valencia, Valencia, Spain. ${ }^{2}$ Ciber of Epidemiology and Public Health (CIBERESP), Instituto de Salud Carlos III, Madrid, Spain. ${ }^{3}$ Department of Clinical Medicine, University Miguel Hernandez of San Juan de Alicante, San Juan de Alicante, Spain. ${ }^{4}$ Department of Medicine, University Jaume I of Castellón, Unión de Mutuas de Castellón, Castellón de la Plana, Spain. ${ }^{5}$ Health Center of Beniganim, Valencia. HTA Working Group SEMERGEN, Valencia, Spain. ${ }^{6}$ Escarval Project, Valencia, Spain. ${ }^{7}$ Centro de Salud Algemesi, Algemesí, Spain. ${ }^{8}$ Department of Preventive Medicine and Public Health, School of Medicine, University of Valencia, Valencia, Spain. ${ }^{9}$ CIBERObn, Instituto de Salud Carlos III, Madrid, Spain. ${ }^{10}$ Department of Environmental Health Sciences, Johns Hopkins Bloomberg School of Public Health, Baltimore, USA. ${ }^{11}$ Hypertension Clinic, Clinical Hospital of Valencia, Avda Blasco Ibañez, 17, 46010 Valencia, Spain.
} 
Received: 21 June 2018 Accepted: 22 August 2018 Published online: 04 September 2018

\section{References}

1. Stefano GB, Challenger S, Kream RM. Hyperglycemia-associated alterations in cellular signaling and dysregulated mitochondrial bioenergetics in human metabolic disorders. Eur J Nutr. 2016;55:2339-45.

2. Paneni F, Lüscher TF. Cardiovascular protection in the treatment of type 2 diabetes: a review of clinical trial results across drug classes. Am J Cardiol. 2017;120(1S):S17-27.

3. Camara S, Bouenizabila E, Hermans MP, Ahn SA, Rousseau MF. Novel determinants preventing achievement of major cardiovascular targets in type 2 diabetes. Diabetes Metab Syndr. 2014;8:145-51.

4. Eranti A, Kerola T, Aro AL, Tikkanen JT, Rissanen HA, Anttonen O, Junttila MJ, Knekt $\mathrm{P}$, Huikuri HV. Diabetes, glucose tolerance, and the risk of sudden cardiac death. BMC Cardiovasc Disord. 2016;16:51.

5. Liang H, Guo YC, Chen LM, Li M, Han WZ, Zhang X, Jiang SL. Relationship between fasting glucose levels and in-hospital mortality in Chinese patients with acute myocardial infarction and diabetes mellitus: a retrospective cohort study. BMC Cardiovasc Disord. 2016;16:156.

6. Liao WI, Wang JC, Chang WC, Hsu CW, Chu CM, Tsai SH. Usefulness of glycemic gap to predict ICU mortality in critically ill patients with diabetes. Medicine (Baltimore). 2015;94:e1525

7. Turnbull FM, Abraira C, Anderson RJ, Byington RP, Chalmers JP, Duckworth WC, et al. Intensive glucose control and macrovascular outcomes in type 2 diabetes. Diabetologia. 2009;52:2288-98.

8. Oh HG, Rhee EJ, Kim TW, Lee KB, Park JH, Yang Kl, Jeong D, Park HK. Higher glycated hemoglobin level is associated with increased risk for ischemic stroke in non-diabetes korean male adults. Diabetes Metab J. 2011;35:551-7.

9. ACCORD Study Group, Gerstein HC, Miller ME, Genuth S, Ismail-Beigi F, Buse JB, Goff DC Jr, Probstfield JL, Cushman WC, Ginsberg HN, Bigger JT, Grimm $\mathrm{RH}$ Jr, Byington RP, Rosenberg YD, Friedewald WT. Long-term effects of intensive glucose lowering on cardiovascular outcomes. N Engl J Med. 2011;364:818-28.

10. ADVANCE Collaborative Group, Patel A, MacMahon S, Chalmers J, Neal B, Billot L, Woodward M, Marre M, Cooper M, Glasziou P, Grobbee D, Hamet P, Harrap S, Heller S, Liu L, Mancia G, Mogensen CE, Pan C, Poulter N, Rodgers A, Williams B, Bompoint S, de Galan BE, Joshi R, Travert F. Intensive blood glucose control and vascular outcomes in pa- tients with type 2 diabetes. $\mathrm{N}$ Engl J Med. 2008;358:2560-72.

11. Duckworth W, Abraira C, Moritz T, Reda D, Emanuele N, Reaven PD, Zieve FJ, Marks J, Davis SN, Hayward R, Warren SR, Goldman S, McCarren M, Vitek ME, Henderson WG, Huang GD, Investigators VADT. Glucose control and vascular complications in veterans with type 2 diabetes. N Engl J Med. 2009:360:129-39.

12. Gerstein HC, Pogue J, Mann JF, Lonn E, Dagenais GR, McQueen M, Yusuf S. HOPE investigators. The relationship between dysglycaemia and cardiovascular and renal risk in diabetes and non-diabetes participants in the HOPE study: a prospective epidemiological analysis. Diabetologia. 2005;48:1749-55.

13. Selvin E, Steffes MW, Zhu H, Matsushita K, Wagenknecht L, Pankow J, Coresh J, Brancati FL. Glycated hemoglobin, diabetes, and cardiovascular risk in nondiabetes adults. N Engl J Med. 2010;362:800-11.

14. Emerging Risk Factors Collaboration, Di Angelantonio E, Gao P, Khan H, Butterworth AS, Wormser D, Kaptoge S, Kondapally Seshasai SR, Thompson A, Sarwar N, Willeit P, Ridker PM, Barr EL, Khaw KT, Psaty BM, Brenner H, Balkau B, Dekker JM, Lawlor DA, Daimon M, Willeit J, Njølstad I, Nissinen A, Brunner EJ, Kuller LH, Price JF, Sundström J, Knuiman MW, Feskens EJ, Verschuren WM, Wald N, Bakker SJ, Whincup PH, Ford I, Goldbourt U, Gómez-de-la-Cámara A, Gallacher J, Simons LA, Rosengren A, Sutherland SE, Björkelund C, Blazer DG, Wassertheil-Smoller S, Onat A, Marín Ibañez A, Casiglia E, Jukema JW, Simpson LM, Giampaoli S, Nordestgaard BG, Selmer R, Wennberg P, Kauhanen J, Salonen JT, Dankner R, Barrett-Connor E, Kavousi M, Gudnason V, Evans D, Wallace RB, Cushman M, D'Agostino RB Sr, Umans JG, Kiyohara Y, Nakagawa H, Sato S, Gillum RF, Folsom AR, van der Schouw YT, Moons KG, Griffin SJ, Sattar N, Wareham NJ, Selvin E, Thompson SG, Danesh J. Glycated hemoglobin measurement and prediction of cardiovascular disease. JAMA. 2014;311:1225-33.

15. Huang Y, Cai X, Mai W, Li M, Hu Y. Association between prediabetes and risk of cardiovascular disease and all-cause mortality: systematic review and meta-analysis. BMJ. 2016 Nov 23;355:15953.

16. Rodkey GV. Electronic Health Records. New Engl J Med. 2010;363:2372-4.
17. Gil-Guillen V, Orozco-Beltran D, Redon J, Pita-Fernandez S, Navarro-Pérez J, Pallares V, Valls F, Fluixa C, Fernandez A, Martin-Moreno JM, Pascual-de-laTorre M, Trillo JL, Durazo-Arvizu R, Cooper R, Hermenegildo M, Rosado L. Rationale and methods of the cardiometabolic Valencian study (Escarvalrisk) for validation of risk scales in Mediterranean patients with hypertension, diabetes or dyslipidemia. BMC Public Health. 2010;10:717.

18. Redon J, Tellez-Plaza M, Orozco-Beltran D, Gil-Guillen V, Pita Fernandez S, Navarro-Pérez J, Pallares V, Valls F, Fernandez A, Perez-Navarro AM, Sanchis C, Dominguez-Lucas A, Sanz G, Martin-Moreno JM, ESCARVAL Study Group. Impact of hypertension on mortality and cardiovascular disease burden in patients with cardiovascular risk factors from a general practice setting: the ESCARVAL-risk study. J Hypertens. 2016;34:1075-83.

19. Tellez-Plaza M, Orozco-Beltran D, Gil-Guillen V, Pita-Fernandez S, NavarroPérez J, Pallares V, Valls F, Fernandez A, Perez-Navarro AM, Sanchis C, Dominguez-Lucas A, Martin-Moreno JM, Redon J, ESCARVAL STUDY GROUP. Renal function and attributable risk of death and cardiovascular hospitalization in patients with cardiovascular risk factors from a registrybased cohort: the Estudio cardiovascular Valencia-risk study. J Hypertens. 2016;34:2266-73.

20. Conroy RM, Pyörälä K, Fitzgerald AP, Sans S, Menotti A, De backer G, De Bacquer $D$, Ducimetière $P$, Jousilahti $P$, Keil U, Njølstad I, Oganov RG, Thomsen T, TunstallPedoe H, Tverdal A, Wedel H, Whincup P, Wilhelmsen L, Graham IM, SCORE project group. Estimation of ten-year risk of fatal cardiovascular disease in Europe: the SCORE project. Eur Heart J. 2003;24:987-1003.

21. Soriguer F, Goday A, Bosch-Comas A, Bordiú E, Calle-Pascual A, Carmena R, Casamitjana R, Castaño L, Castell C, Catalá M, Delgado E, Franch J, Gaztambide S, Girbés J, Gomis R, Gutiérrez G, López-Alba A, Martínez-Larrad MT, Menéndez E, Mora-Peces I, Ortega E, Pascual-Manich G, Rojo-Martínez G, Serrano-Rios M, Valdés S, Vázquez JA, Vendrell J. Prevalence of diabetes mellitus and impaired glucose regulation in Spain: the Di@bet.es study. Diabetologia. 2012 Jan;55(1):88-93.

22. National Institute of Statistics, Spain. http://www.ine.es/dyngs/INEbase/es/ categoria.htm?c=Estadistica_P\&cid=1254735573175.

23. Greenland P, Alpert JS, Beller GA, Benjamin EJ, Budoff MJ, Fayad ZA, Foster E, Hlatky MA, Hodgson JM, Kushner FG, Lauer MS, Shaw LJ, Smith SC Jr, Taylor AJ, Weintraub WS, Wenger NK, Jacobs AK, Smith SC Jr, Anderson JL, Albert N, Buller CE, Creager MA, Ettinger SM, Guyton RA, Halperin JL, Hochman JS, Kushner FG, Nishimura R, Ohman EM, Page RL, Stevenson WG, Tarkington LG, Yancy CW, American College of Cardiology Foundation; American Heart Association. 2010 ACCF/AHA guideline for assessment of cardiovascular risk in asymptomatic adults: a report of the American College of Cardiology Foundation/American Heart Association task force on practice guidelines. J Am Coll Cardiol. 2010;56:e50-103.

24. Rydén L, Grant PJ, Anker SD, Berne C, Cosentino F, Danchin N, Deaton C. Guidelines on diabetes, pre-diabetes, and cardiovascular diseases developed in collaboration with the EASD: the task force on diabetes, pre-diabetes, and cardiovascular diseases of the European Society of Cardiology (ESC) and developed in collaboration with the European Association for the Study of diabetes (EASD). Eur Heart J. 2013;34:3035-87.

25. Gore MO, McGuire DK. A test in context: hemoglobin a(1c) and cardiovascular disease. J Am Coll Cardiol. 2016;68:2479-86.

26. Roussel R, Steg PG, Mohammedi K, Marre M, Potier L. Prevention of cardiovascular disease through reduction of glycaemic exposure in type 2 diabetes: a perspective on glucose-lowering interventions. Diabetes Obes Metab. 2018;20:238-44.

27. Zhao W, Katzmarzyk PT, Horswell R, Wang Y, Johnson J, Hu G. HbA 1 and coronary heart disease risk among diabetic patients. Diabetes Care. 2014;37:428-35.

28. Chen YY, Lin YJ, Chong E, Chen PC, Chao TF, Chen SA, Chien KL. The impact of diabetes mellitus and corresponding $\mathrm{HbA1c}$ levels on the future risks of cardiovascular disease and mortality: a representative cohort study in Taiwan. PLoS One. 2015;10:e0123116.

29. Currie CJ, Peters JR, Tynan A, Evans M, Heine RJ, Bracco OL, Zagar T, Poole $\mathrm{CD}$. Survival as a function of $\mathrm{HbA}(1 \mathrm{c})$ in people with type 2 diabetes: a retrospective cohort study. Lancet. 2010;375:481-9.

30. Eeg-Olofsson K, Cederholm J, Nilsson PM, Zethelius B, Svensson AM, Gudbjörnsdóttir S, Eliasson B. New aspects of HbA1c as a risk factor for cardiovascular diseases in type 2 diabetes: an observational study from the Swedish National Diabetes Register (NDR). J Intern Med. 2010;268:471-82.

31. American Diabetes Association. 9. Cardiovascular Disease and Risk Management: Standards of Medical Care in Diabetes-2018. Diabetes Care. 2018;41(Suppl 1):S86-S104. 